\title{
Jogo e mediação social: um estudo sobre o desenvolvimento e a aprendizagem de alunos do ensino fundamental
}

\author{
CLAUDIA BERTONI FITTIPALDI*
}

\section{RESUMO}

O texto apresenta o resultado de um estudo fundamentado na vertente histórico-cultural de Vygotsky, cujo principal objetivo foi verificar se as crianças adquirem novos conhecimentos, desenvolvem novas habilidades e empregam novas estratégias, ao jogar com o apoio da mediação social. Realizaram-se quatro estudos de casos com meninos de nove anos, da $3^{a}$ série do Ensino Fundamental de uma escola pública. A coleta de dados contou com o instrumento utilizado por Ribeiro (2001) - Jogo das Boas Perguntas - adaptado em razão dos objetivos propostos na pesquisa. Inicialmente, os alunos conheceram o material, as regras do jogo e classificaram as figuras de acordo com o conhecimento, as habilidades e estratégias que já possuíam, sendo a mediação nesse momento vaga e imprecisa. Posteriormente, houve intervençóes mais incisivas e diretas visando a otimizar as aprendizagens necessárias para bem-jogar. Por último, verificou-se a extensão da aprendizagem adquirida. Os resultados indicam que, quando se joga com o apoio de uma mediação que considera os níveis de desenvolvimento real, as possibilidades de aprendizagem se ampliam.

Palavras-chave: aprendizagem, desenvolvimento da criança, jogos, processo ensinoaprendizagem.

\footnotetext{
*Professora do Curso de Pedagogia da Universidade Guarulhos (clabertoni@ig.com.br).
} 


\section{RESUMEN}

El texto presenta el resultado de un estudio que se fundamenta en la vertiente históricocultural de Vygotsky, cuyo principal objetivo fue verificar si los niños, al jugar con el apoyo de una mediación social, adquieren nuevos conocimientos, desarrollan nuevas habilidades y emplean nuevas estrategias. Se realizaron cuatro estudios de caso con niños de nueve años, de

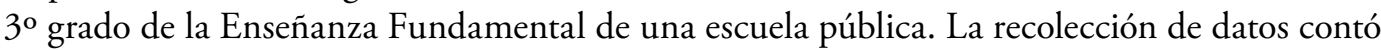
con el instrumento utilizado por Ribeiro (2001) - Juego de las buenas preguntas - adaptado en vista a los objetivos propuestos en la investigación. En primer lugar, los alumnos conocieron el material, las reglas del juego y clasificaron las figuras según el conocimiento, las habilidades y las estrategias que ya poseían. En esta etapa la medición fue vaga e imprecisa. Luego hubo intervenciones más incisivas y directas que tenían el objetivo de optimizar los aprendizajes necesarios para jugar-bien. Por último, se verificó la extensión del aprendizaje adquirido. Los resultados indican que, cuando se juega con el apoyo de un mediador que considera los niveles de desarrollo real, se amplían las posibilidades de aprendizaje.

Palabras clave: aprendizaje, desarrollo del niño, juegos, proceso de enseñanza-aprendizaje.

\section{ABSTRACT}

This article presents the results of a study based on Vygotsky's Historic-Cultural approach. Its main objective was to investigate whether children acquire new knowledge, develop new abilities and use new strategies when they play a game with the support of social mediation. Four case studies were carried out with $3^{\text {rd }}$ grade 9-year-old boys, of a public school. The data was collected by means of an instrument used by Ribeiro (2001) - the Good Question Game -, which was adapted according to the study's goals. First the students were introduced to the material, learned the rules of the game and classified the pictures according to the knowledge, abilities and strategies they already had. At that stage mediation was vague and unfocused. Later, more incisive and direct interventions took place so as to enhance the learning strategies needed to play-well. Finally, the extension of acquired learning was assessed. The results showed that when one plays with the support of a mediation that takes into account the students' actual levels of development, there are gains in the development that intensify learning possibilities.

Keywords: learning, child development, games, teaching-learning process. 


\section{INTRODUÇÃO}

É interessante notar que enquanto na Educação Infantil o jogo é um recurso bastante utilizado, no Ensino Fundamental ele vai sendo excluído paulatinamente do processo educativo, como se não houvesse mais espaço na sala de aula para ele, ou não fosse um bom recurso para realmente promover a aprendizagem de conceitos e raciocínios tidos com centrais para o sucesso escolar.

No entanto, Vygotsky $(1989,1994)$ aponta que os jogos podem criar uma Zona de Desenvolvimento Próximo (ZDP), pois as crianças, quando jogam, utilizam conhecimentos já adquiridos e constroem outros; articulam seus conceitos cotidianos e científicos. O autor afirma, ainda, que os jogos possibilitam ao professor conhecer e avaliar melhor o aluno, e, assim, proporcionar avanços em sua aprendizagem e desenvolvimento.

Isto posto, relata-se neste artigo uma pesquisa cujo objetivo foi verificar se crianças do Ensino Fundamental adquirem novos conhecimentos, desenvolvem novas habilidades e empregam novas estratégias cognitivas, ao fazer uso de jogos com o apoio da mediação social. Busca-se, com isto, aprofundar a relação entre jogos, aprendizagem e desenvolvimento, tendo por fundamentação a perspectiva sócio-histórica.

\section{O JOGO NA PERSPECTIVA SÓCIO-HISTÓRICA}

Ao estudar sobre jogos, Vygotsky (1989) não buscou classificá-los, mas apontar suas características definidoras e analisar sua evolução e importância para o processo de aprendizagem e desenvolvimento. Ao contrário do que comumente se observa na literatura a respeito desse tema, para o autor o prazer náo é concebido como uma de suas características definidoras, uma vez que esse só ocorre quando a criança obtém um resultado favorável. Para ele, as características que definem o jogar são a imaginaçáo, a imitaçáo e as regras, como bem relata Elkonin (1998). Tais características estão presentes em todo jogo, e a preponderância, ora de uma, ora de outra, dá-se em funçáo da evoluçáo que o jogo sofre no decorrer do desenvolvimento da criança. Em tese, na fase pré-escolar, a imaginação está explícita e as regras implícitas; já na fase escolar, as regras estão explícitas e a imaginação implícita ${ }^{1}$.

\footnotetext{
${ }^{1}$ Como para Vygotsky a regra é uma das características definidoras do jogo - que nele se encontra presente, seja implícita ou explicitamente -, seria incoerente utilizar o termo "jogos de regras". Por esse motivo e por ser "jogos de regras" uma terminologia piagetiana, optou-se pelo termo "jogos com regras explícitas" para referir-se àqueles utilizados pelas crianças em idade escolar (que é a de interesse no estudo relatado).
} 
Sob tal perspectiva, Vygotsky (1989) explica que a partir da idade pré-escolar os campos da percepçáo visual e do significado se afastam: o pensamento separa-se dos objetos e a ação surge mais das ideias do que das coisas, fato que possibilita um objeto influir semanticamente em outro. Ao criar uma situação imaginária na qual assume um papel, a criança é levada a imitar o comportamento de alguém/algo. Esta imitação envolve implicitamente regras de comportamento. Durante a fase pré-escolar, portanto, a imaginação está explícita e as regras implícitas. Leontiev (1998) esclarece que embora o objeto possua um significado próprio que não se altera no decorrer do jogo, ele adquire um sentido novo e particular para a criança, em razão das regras implícitas presentes na situação.

À medida que o desenvolvimento infantil caminha, o inverso ocorre: as regras tornam-se explícitas e a imaginação implícita, caracterizando a fase escolar. Com a possibilidade de jogar baseado em regras, estabelece-se nova relação entre significado e campo visual e entre as situaçóes imaginárias existentes no pensamento e as situaçóes reais. Como é possível observar em uma das anotaçóes de Vygotsky para a conferência sobre psicologia infantil, no "escolar, ocorre o aparecimento do campo semasiológico interior, independente, não sobreposto, mas coordenado com o exterior" (apud Elkonin, 1998, p. 427).

Além da imaginação e das regras, Vygotsky (1933, apud Elkonin, 1998) destaca que também existe, em todo jogo, a imitação: em uma situação fictícia há sempre um aspecto de criação e de imitação, visto que o indivíduo nunca parte do zero, mas sim de algo já criado, combinando-o de forma nova com suas diferentes experiências. Assim, a imitação tem papel fundamental no desenvolvimento da criança, pois permite que ela faça aquilo que viu o outro fazer, aquilo que aprendeu observando o outro. Por isso, a imitação não pode ser entendida como simples atividade mecânica mas, sim, como a reconstruçáo individual daquilo que a criança aprendeu a partir dos outros.

Tais colocaçôes levam a concluir que o jogo, tal como define Vygotsky, permite à criança se apropriar do mundo sociocultural em que vive. Por seu intermédio, ela aprende, reconstrói algo que observou nos outros, esforça-se para agir segundo os limites (regras) que a situação lhe impõe. No jogo, os objetos/ações dos outros adquirem novo sentido e são re-significados, de modo que a ação da criança passa a ser norteada pela significação que deu a esses objetos e situaçôes. É, pois, a significação da açáo, palavra ou objeto - e não a ação, a palavra ou o objeto em si - o elemento que permanece quando ocorre a conversão de uma ação interpessoal para uma intrapessoal (processo definido por Vygotsky como "internalizaçáo"). 
A internalização, como explica Pino (1992), é entendida como a reconstrução individual de algo social, que se concretiza pela negociação entre o significado público/social e as diferentes interpretaçóes/sentidos privados. Tal negociação ocorre nas e pelas interaçóes entre o sujeito e os agentes mediadores de cultura - pais, professores e colegas mais experientes - por meio de instrumentos e signos culturalmente construídos. A internalização dá origem às funçôes psicológicas superiores (FPS), tipicamente humanas, reguladas pelo próprio indivíduo (imaginação, memória voluntária, resolução de problemas, raciocício lógico, pensamento abstrato, atenção e comportamentos voluntários) e mediadas por signos e instrumentos.

Em relaçáo ao jogo, Vygotsky chama a atenção para sua importância como instrumento mediador no desenvolvimento das FPS. Na idade escolar, a criança passa a interessar-se mais pelo outro e por compartilhar açóes. O jogo com regras explícitas, típico das crianças dessa idade, ao mesmo tempo que propicia essa interação, estabelece limites claros, segundo os quais a criança deve agir. Para tanto, a criança deverá compreender as regras e o desenvolvimento do jogo, prestando atençáo nas jogadas que o outro faz (caso o jogo envolva mais pessoas) e nas suas próprias, analisando-as e interpretando-as. Para tanto, várias FPS, como o levantamento de hipóteses, a avaliação das jogadas realizadas para resolver a situação-problema que o jogo impóe, a percepção e a abstração do pensamento, devem ser ativadas. Logo, ao que parece, o jogo com regras explícitas promove e exercita as FPS, impulsionando o desenvolvimento cognitivo.

Nos jogos, a criança passa de um papel passivo, de mero receptor de informaçóes, para um papel ativo, no qual pensar se faz necessário. No jogo com regras explícitas, uma situaçáo-problema é colocada para a criança, desafiando-a a buscar a solução. $\mathrm{O}$ jogo permite, ainda, que o professor identifique: a) a forma como o aluno está pensando, analisando as jogadas que realiza e rastreando a lógica do seu raciocínio, bem como os motivos que o levaram a acertar ou errar; b) o que o aluno já consegue resolver sozinho - nível de desenvolvimento real; e c) as dificuldades do aluno, o tipo de ajuda que precisa receber do professor ou dos companheiros - nível de desenvolvimento próximo. Segundo Vygotsky, surge, então, no jogo, a "zona de desenvolvimento próximo”, ou seja, a distância metafórica entre o nível de desenvolvimento real e o nível de desenvolvimento próximo da criança. De fato, ao criar uma zona de desenvolvimento próximo, o jogo permite a ação intencional do outro, que, se bem sucedida, permite a reduçáo dessa distância, uma vez que a criança reconstrói, no plano intrapessoal, o que em princípio existe somente como virtual, transformando o nível de desenvolvimento próximo em nível de desenvolvimento 
real, impulsionando a aprendizagem e o desenvolvimento de funçóes psicológicas que estão em via de se consolidar.

Sob este prisma, o jogo com regras explícitas passa a ser visto como um promotor de alterações nas estruturas cognitivas e não simplesmente como um meio de assimilar a realidade. Assim entendido, o jogo vai ao encontro da perspectiva sócio-histórica, que postula haver uma relação recíproca entre aprendizagem e desenvolvimento: a aprendizagem náo fica à espera do desenvolvimento, mas a ele se articula. Uma aprendizagem bem organizada impulsiona o desenvolvimento que, ao avançar, permite novas aprendizagens. Cabe basicamente ao professor criar "condiçóes para que determinados progressos cognitivos se desenvolvam, sem os implantar diretamente na criança” (Vygotsky, apud Van Deer Veer, 1996, p. 358).

$\mathrm{O}$ jogo é, efetivamente, uma dessas condições. Estratégia cognitiva útil para promover a aprendizagem, ele proporciona uma situação interativa entre professor-aluno e aluno-aluno, bem como o confronto de ideias diferentes, o que leva a novas descobertas e avanços que só aconteceriam espontaneamente, com um custo pessoal muito elevado. O jogo, dessa forma, faculta ao professor avaliar seu aluno não em razão apenas do que já é capaz de realizar sozinho, mas também em função do que está em vias de se consolidar, graças à ajuda de alguém mais experiente. Pressupóe-se, assim, que a escola deveria empregar o jogo como recurso de ensino, uma vez que jogando a criança não fica apenas no que já domina, vai além, ou seja, aciona as FPS que estão prestes a se estabelecer.

Nesse sentido, autores filiados à abordagem sócio-interacionista de Vygotsky (Ferrara; Brown; Campione, 1986; Haywood; Switsky, 1986; Lidz, 1987; Tzuriel; Klein, 1987, entre outros) também repensam a avaliação do desempenho intelectual, como expóe Linhares (1995). De fato, à medida que a aprendizagem é deliberadamente mediada pode ocorrer modificação cognitiva no que tange ao patamar inicial de desempenho avaliado. Surge a modalidade de avaliaçáo assistida (Campione, 1989) ou dinâmica (Haywood; Switsky, 1986), cujo objetivo não se atém em detectar o que o aluno já é capaz de realizar sozinho, mas pretende verificar as possibilidades que melhor auxiliam o avaliando a aprender.

Com esse tipo de avaliação, é possível detectar: diferenças intragrupo, dificuldades específicas, a sensibilidade do educando à instrução, estratégias utilizadas para a resolução de problemas, recursos potenciais para transferir e generalizar a aprendizagem. A ênfase está, portanto, no processo de aprendizagem e náo no produto. Com isso, é possível evitar muitas situaçóes de fracasso e a rotulação de muitos sujeitos como portadores de "problemas de aprendizagem". 
Cabe à escola e, em especial, ao professor, priorizar as interaçóes aluno-aluno, aluno-professor, utilizando recursos que as facilitem, para promover tanto a aprendizagem quanto o desenvolvimento. $\mathrm{O}$ jogo, nessa perspectiva, coloca-se como um instrumento que faculta ao professor uma intervenção intencional visando a tais promoçóes. Além disso, também possibilita à criança articular conceitos cotidianos, aprendidos na vida diária por meio de sua experiência, observação, manipulação e vivência direta, e conceitos científicos, construídos pela mediação social, pela ação sistemática e intencional de pessoas mais experientes, na busca de desenvolver uma percepção mais generalizante do real, e na tomada de consciência do significado dos conceitos que emprega.

Quando a criança chega à escola já traz consigo uma série de conceitos cotidianos que não podem ser ignorados. $\mathrm{O}$ trabalho escolar é, justamente, articular esses conceitos com os de natureza científica, uma vez que, como explica Vygotsky (2001, p. 345), estes últimos "começam sua vida pelo nível que o conceito cotidiano da criança ainda não atingiu em seu desenvolvimento", ou seja, estes conceitos estáo inter-relacionados: parte-se das generalizaçóes mais elementares que a criança foi capaz de fazer para se chegar a uma generalização mais elaborada, abstrata.

Atrelado ao desenvolvimento de um conceito científico está o desenvolvimento das FPS: para formar um conceito, a criança precisa de atenção voluntária, memória lógica, possibilidade de comparar, distinguir, classificar, deduzir, inferir, entre outras operaçôes intelectuais. Isto só salienta a importância dos jogos no processo ensino-aprendizagem, uma vez que por seu intermédio se criam condiçóes para que as crianças comparem, estabeleçam relaçóes, diferenciem e desenvolvam a atenção voluntária, o raciocínio, o pensamento abstrato.

Por meio do jogo, a criança é convidada a compreender (e não a simplesmente memorizar) e, partindo do que já sabe, elaborar novos conceitos que permitem, à medida que joga, maior generalização do pensamento. O professor, por sua vez, conta, no jogo, com a possibilidade de intervir adequadamente, evitando que dificuldades se instalem e o fracasso escolar se torne uma constante. Pelo exposto, depreende-se que o jogo, com base no que a criança já sabe, ao criar situações de interação social, ao propiciar o desenvolvimento das FPS, cria uma ZDP que pode ser ativada por professores e pessoas mais experientes, para promover, nas geraçóes mais jovens, um grau crescente de generalização do pensamento. Com isso, a escola auxilia a criança no processo de formação de conceitos, e potencializa, assim, a produção do conhecimento. 


\section{MÉTODO}

\section{Procedimento da coleta de dados}

A pesquisa foi realizada em uma escola estadual de Ensino Fundamental (1 a a $4^{\mathrm{a}}$ série), situada em um bairro de classe média da zona leste da cidade de São Paulo. A pesquisadora solicitou às professoras da $3^{\mathrm{a}}$ série que indicassem alunos, de nove anos, que facilmente acompanhavam o grupo do ponto de vista da aprendizagem e alunos que não o faziam.

Para garantir a idoneidade da seleção - e evitar que fosse pautada em quaisquer outras características das crianças - foi aplicado o Teste de Desempenho Escolar (TDE) (Stein, 1994), composto pelos subtestes de leitura, escrita e aritmética. O objetivo era avaliar o desempenho escolar dos alunos de acordo com critérios préestabelecidos para a idade/série. Dos oito meninos indicados pelas professoras, foram selecionadas quatro crianças tendo por critério o resultado obtido no TDE, a saber: um menino com desempenho superior ao esperado para a faixa etária e o nível escolar (Carlos, identificado por C); um menino cuja atuaçáo era a esperada para a idade e série (Cauique, identificado por Ce); 2 meninos com desempenho inferior ao esperado para a faixa etária e escolar (Breno e Rick, identificados na pesquisa por $\mathrm{B}$ e $\mathrm{R}$, respectivamente) $)^{2}$.

O procedimento de coleta de dados seguiu a abordagem de avaliação assistida em situação de resolução de problemas. A aplicação desse procedimento fez-se por meio do Jogo das Boas Perguntas - JBP (Ribeiro, 2001), composto por dois conjuntos idênticos com vinte e uma figuras de animais: 7 insetos, 7 aves e 7 mamíferos. Este jogo consiste em, por meio de apenas seis perguntas, que só podem ser respondidas com sim ou não, descobrir a figura escondida pelo adversário. Para tanto, requer que a criança classifique as figuras mediante um atributo comum, tendo em vista que este conhecimento lhe permite fazer perguntas mais abrangentes (chamadas, no jogo, de "boas perguntas"), que implicam um número maior de descartes. A coleta de dados ocorreu em três fases: assistência indireta, assistência direta e pós-teste.

$\mathrm{Na}$ fase de assistência indireta, a intervenção foi bastante sutil: as crianças receberam instruçóes padronizadas, exploraram o material, conheceram as regras do jogo e classificaram as figuras de acordo com seu conhecimento, suas habilidades e estratégias. Em seguida, a pesquisadora apresentou à criança o "Jogo das Boas Perguntas". Nesta fase, foram realizadas cinco partidas para que a criança conhecesse as regras do jogo e as exercitasse, bem como possibilitar que agisse da

${ }^{2}$ Os nomes das crianças foram alterados, a fim de se garantir o anonimato. 
maneira que lhe parecesse a mais adequada para vencer o jogo. No decorrer das partidas, caso a criança não alterasse a disposição espacial das figuras, era sugerido que as arrumasse de forma a facilitar "boas perguntas". O objetivo, aqui, era dar uma pista para que a criança pudesse dispor os animais de maneira ordenada e, assim, fosse capaz de fazer mais facilmente "boas perguntas". Da mesma maneira, se no decorrer do jogo as perguntas náo se alterassem, a pesquisadora questionava se não havia outra forma de perguntar, para descobrir a figura que se encontrava escondida, mas sem lhe ensinar como proceder para ganhar. Caso acertasse, a pesquisadora também conversava com o jogador para tentar identificar que aspectos lhe possibilitaram a descoberta. Cada vez que ganhava o jogo, a criança tinha um ponto anotado no placar.

$\mathrm{Na}$ segunda fase - assistência direta -, ocorreram intervençóes intencionais, incisivas e precisas durante o JBP com figuras de animais, bem como a troca de papéis (pesquisador/aluno; aluno/aluno), a fim de otimizar a aprendizagem necessária para o bem-jogar. Buscando a otimizaçáo da aprendizagem, a mediaçáo deu-se tanto por ajuda concreta quanto por ajuda verbal.

No caso da ajuda concreta, utilizaram-se as figuras do jogo e a coleçáo $O s$ bichos (Civita, s.d.) como materiais de suporte ao raciocínio dedutivo de exclusão. A pesquisadora não só sugeria à criança, no momento em que esta jogava, que organizasse as figuras com base em um critério lógico; que excluísse a figura em função das respostas obtidas e que consultasse os livros para fornecer as informaçôes necessárias, como a própria pesquisadora $(\mathrm{P})$, na sua vez de descobrir a figura escondida, fazia questão de: a) organizar as figuras, explicitar para a criança o critério que estava utilizando para separá-las e como isto poderia ajudá-la a descobrir mais facilmente a que estava escondida; b) retirar todas as figuras possíveis pela resposta que obtinha; e c) consultar os livros para o fornecimento das informaçóes que se fizessem necessárias.

No caso da ajuda verbal, diferentes níveis foram definidos:

- Nível 1: feedback informativo sobre o desempenho da criança quanto: à qualidade da pergunta formulada, seu poder de restrição de alternativas e o seguimento da instrução inicial. Exemplo:

Cauique, depois de saber que o animal era mamífero, perguntou: É criado em casa?

P: Não.

Ce: (faz o descarte inverso). 
P: Você perguntou se era criado em casa, eu disse não. Leão é criado em casa?

Ce: Não (ri e bate com a mão na testa).

P: Porco, cavalo, vaca são criados dentro de casa?

Ce: Não.

P: Você descartou as figuras erradas.

- Nível 2: exemplo de "Boa Pergunta", oferta de perguntas relevantes, que abrangiam o maior número possível de figuras a serem eliminadas. Exemplo:

P: (na primeira jogada, de troca de papéis com Breno) É mamífero?

B: Não.

P: Se não é mamífero, então eu posso tirar todos os mamíferos: vaca, cavalo, cachorro, leão, coelho, macaco e porco. Olha só quantas figuras eu tirei com uma pergunta só! Foi uma boa pergunta esta.

- Nível 3: análise comparativa de estímulos, ou seja, análise das semelhanças e diferenças entre as figuras. Exemplo:

Depois de Rick separar os animais em dois grupos - os que voam e os que não voam - a P perguntou: Dos que voam, quais são aves?

R: (não responde).

P: Todos aqui são aves?

R: (faz sinal com a cabeça que sim).

P: Então escolhe e aponta para mim uma ave.

R: (aponta o papagaio).

P: O papagaio? Ele tem pena?

R: (faz com a cabeça que sim).

P: Tem bico?

R: (faz sinal positivo com a cabeça).

P questiona da mesma forma, uma a uma, todas as outras aves, recebendo como resposta um sinal afirmativo.

P: Barata tem bico?

R: Não. 
P: Tem pena?

R: Só tem asa.

P faz o mesmo com outros insetos e acrescenta: Entáo, os animais que têm bico e pena são as aves e estes outros aqui (apontando para os insetos) são os insetos.

- Nível 4: exemplo de pergunta com ausência ou baixo poder de exclusão: a pesquisadora proporcionava exemplo direto de pergunta ineficiente ou pouco eficiente para avançar no jogo.

Durante sua vez de tentar descobrir o animal escondido, a pesquisadora fez perguntas pelo nome do animal, desde o início da partida, realizando o descarte correspondente:

P: É o cachorro?

R: Não.

P: Ih! Não foi uma boa pergunta, só tirei uma figura!

(em seguida) É a joaninha? O macaco? O pardal? O pato? É a borboleta?

Para cada pergunta a pesquisadora obteve como resposta "Não", realizando os descartes correspondentes.

P: As perguntas que eu fiz foram boas?

R: Não, só tirou uma figura.

- Nível 5: demonstração de um exemplo de solução pela pesquisadora que, verbalizando, demonstrava, em um exemplo completo, as estratégias de "boas perguntas", ou seja, perguntas com forte poder de eliminação das figuras. Exemplo:

Pesquisadora na troca de papéis com Breno: Mama?

B: Não (os mamíferos são eliminados).

P: Voa?

B: Não (aves e insetos voadores são eliminados).

P: É ave?

B: Sim (insetos não voadores são eliminados).

P: É o pinguim?

B: Sim (mostrou o papel escrito pinguim). 

P: Fiz boas perguntas?
B: Fez.
P: Por quê?
B: Tirou muitas figuras cada vez que perguntava.
P: É uma boa pergunta ficar perguntando pelo nome do animal des- de o começo do jogo?
B: Não.

Nesta fase de assistência direta, como já foi esclarecido, além das intervençôes acima explicitadas, ocorreu também a troca de papéis entre a pesquisadora e os alunos, assim como entre os próprios alunos. Inicialmente, foram realizadas três partidas com mediação só da pesquisadora e sem troca de papéis: ela apenas fazia perguntas, tentando descobrir o animal escondido. As partidas com troca de papéis não tiveram um número fixo definido, pois variavam de acordo com o desempenho da criança durante o jogo. Cada uma delas jogava uma série com a pesquisadora, invertendo os papéis. Posteriormente, a pesquisadora formava duplas, em função de como as crianças demonstraram jogar. Organizaram-se duplas assimétricas, ou seja, uma criança que jogou muito bem interagia com outra que não conseguiu o mesmo sucesso, e duplas simétricas, compostas de crianças que jogaram bem as partidas. Nessas duplas, também ocorreu a inversão de papéis.

$\mathrm{Na}$ terceira etapa - pós-teste -, foi verificado se, e em que extensão, a participação do outro, por meio das interaçóes entabuladas, implicou ganhos em termos dos conhecimentos pertinentes, ou seja, se houve manutenção e transferência da aprendizagem de habilidades e estratégias para um novo conjunto de figuras (composto por 7 alimentos, 6 peças de vestuário e 6 objetos escolares). Para tanto, foram realizadas duas partidas do JBP com figuras de animais, sem troca de papéis, e mais duas partidas do JBP, também sem troca de papéis, com o novo conjunto de figuras. Ao término da investigaçáo, a pesquisadora conversou com as crianças, procurando saber: a) se havia sido fácil ou difícil jogar e por quê; b) em que momento o jogo havia sido mais fácil ou mais difícil e por quê; c) se tinha visto alguma coisa que não conhecia e passou a conhecer. Em caso afirmativo, o que ela acreditava ter possibilitado esse conhecimento.

\section{RESULTADOS}

Para analisar os dados coletados, acrescentou-se às categorias relacionadas às condutas cognitiva e afetiva, elencadas por Ribeiro (2001), a mediação social. No 
que se refere às condutas cognitivas, observou-se o respeito às regras do jogo, o tipo de pergunta e de descarte realizados, bem como a necessidade de mediação social, ou, em outras palavras, a necessidade de intervenção intencional, por parte da pesquisadora, para promover a aprendizagem de conhecimentos, o desenvolvimento de habilidades e o uso de novas estratégias, tendo por base o desenvolvimento real e proximal do aluno e de crianças mais experientes que, buscando ganhar, mostravam aos menos experientes como fazer boas perguntas. Já com relação às atitudes ou aspectos afetivos das condutas, foram observados: o envolvimento, a concentração, a flexibilidade, a tolerância à frustração, a cooperação e a tranquilidade da criança ao jogar.

$\mathrm{Na}$ fase de assistência indireta das partidas, foi possível verificar, pelo desempenho de cada criança, que as estratégias cognitivas utilizadas por elas para ganhar o jogo eram pouco ou nada eficientes. Assim, no que diz respeito ao cumprimento das regras, embora todos aceitassem o término da partida, independentemente do resultado obtido, C., em uma jogada, e B., mais frequentemente, fizeram perguntas que não poderiam ser respondidas com "sim" ou "não", como demonstram os exemplos: C: “Anda ou voa?” B: "É pequeno ou grande?” Revelando, dessa maneira, a compreensão parcial das regras do jogo.

No que tange à organização das figuras, nenhum dos jogadores as agrupou de acordo com um critério lógico, permanecendo inalterada a sua disposição desde o início das partidas, apesar da sugestáo da pesquisadora.

Quanto às perguntas, estas se pautavam nos conhecimentos cotidianos e/ ou na percepção imediata, sendo, em sua maioria, de qualidade ineficiente, pois:

a) referiam-se ao nome da figura que julgavam estar escondida, indicando a tentativa de identificá-la de imediato, embora houvesse muitas figuras em jogo. Exemplo: Rick, em sua quinta partida, perguntou: "Galo? Cavalo? Porco? Macaco? Pato? Pinguim?";

b) eram perguntas desnecessárias, pois a informação já havia sido obtida anteriormente. Exemplo: ao restar apenas animais com quatro patas no jogo, B. pergunta se o animal tem seis ou mais patas, náo permitindo, assim, eliminar figura alguma;

c) reportavam-se a uma qualidade que só um único animal possuía, apesar de estarem em jogo mais de três figuras. Exemplo: após saber pelas perguntas precedentes que o animal tinha asas, Ce. perguntou: "Faz mel?" Referindose à qualidade que é específica da abelha. 
Quando perguntas mais abrangentes, ou seja, que envolviam um atributo comum a pelo menos duas figuras em jogo, eram formuladas (fossem elas de qualidade intermediária - perguntas que dependendo da resposta obtida poderiam eliminar muitas peças, $71 \%$ ou mais, ou poucas peças, $29 \%$ ou menos - ou perguntas de boa qualidade - que permitiam descartar, independentemente da resposta, 30 a $70 \%$ das figuras em jogo), as inclusóes devidas nem sempre eram feitas. Com frequência, não sabiam mais o que perguntar quando descobriam a que grupo pertencia o animal escondido (aves, por exemplo). Passavam, então, a fazer perguntas menos eficientes e a depender totalmente do acaso para ganhar o jogo, como se pode observar nos exemplos a seguir:

Na quinta jogada da segunda partida, Ce. perguntou: “Tem antenas?” Neste momento do jogo, a resposta obtida para esta pergunta só permitia $29 \%$ de descarte, portanto, de qualidade intermediária.

Na primeira jogada da terceira partida, B. perguntou: "É ave?" Pergunta que possibilitava eliminar 33,3\% das figuras. Em seguida indagou: "Galo?"

P: Não. Galo não é ave?

B: Não.

P: Como você sabe o que é ave ou não?

B: Sei que eu sei.

3a jogada:

B: Vaca?

P: Não. Tem outra pergunta que você pode fazer para descobrir a figura escondida?

B: (não responde).

4a jogada:

B: Pequeno ou grande?

P: (esclarece que só pode responder "sim" ou "não" e avisa que só tem mais duas perguntas para fazer).

$5^{\text {a jogada: }}$

B: Vaca?

P: Não. Você já perguntou se era vaca e eu disse que não, se quiser pode tirar as figuras que já sabe que não é.

B: (não tira). 

6a jogada:
B: Cavalo?
P: Não. Que outra pergunta você poderia fazer para descobrir que era o porco?
B: Se era gordo ou não.
P: Tem outra pergunta que você poderia fazer?
B: Não.

Pelo último exemplo, é possível também verificar, como já esclarecido anteriormente, que a mediação na fase de assistência indireta foi muito vaga e imprecisa, uma vez que o objetivo nesse momento náo era ensinar a criança como proceder para ganhar, mas possibilitar que reconhecesse o material e tomasse conhecimento das regras do jogo, bem como permitir à pesquisadora verificar o desempenho real das crianças, ao utilizarem o conhecimento, as habilidades e as estratégias que já possuíam.

Com relação aos descartes (com exceção de Carlos que realizou alguns corretos), eles eram, na maioria das vezes, ineficientes (ausentes ou inverso) - como pode-se observar no exemplo da $5^{a}$ jogada, em que Breno não descarta as figuras -, ou intermediários (implícitos ou parcialmente corretos). As justificativas apresentadas ao realizá-los - ou ao ganhar o jogo nesta fase -, também sinalizavam que, no caso principalmente de Breno e Rick, havia a percepção de que se tratava de uma relação de exclusão, muito embora a escolha do animal se desse por acaso. As justificativas de Carlos e Cauique baseavam-se em perguntas anteriores, ainda que existissem outros animais que, pela pergunta feita, também pudessem ser excluídos.

Exemplos:

Rick perguntou, em sua primeira jogada: "É o cachorro?” Resposta: "Não." Nas perguntas subsequentes: "Tucano? Pato? Pomba? Cavalo? Joaninha?" (Não menciona nas jogadas seguintes o cachorro, apesar de não tê-lo descartado explicitamente).

Carlos, na segunda jogada da terceira partida, indagou se o animal conseguia voar e, ao obter como resposta não, descartou aves voadoras e insetos, com exceção da abelha, realizando, portanto, um descarte parcialmente correto.

$\mathrm{Na}$ fase de assistência direta, com uma mediação mais precisa e incisiva, houve uma melhora crescente na qualidade das perguntas e dos descartes. As crianças 
passaram a jogar com base não só nas regras explícitas do jogo como, também, nas inclusóes de classe feitas por pareamento nome/referente, que levaram a uma maior generalização e abstração.

Das quatro crianças, Rick foi o único que realmente necessitou de todos os níveis do gradiente de mediaçáo, no que se refere à ajuda concreta (organização das figuras; exclusão dos cartóes com as figuras, em função das respostas obtidas e consulta aos livros) e verbal (níveis: 1- feedback; 2 - exemplo de boa pergunta; 3 - análise comparativa de estímulos; 4 - exemplo de pergunta com ausência ou baixo poder de exclusão; e 5 - demonstraçáo de um exemplo de soluçáo pela pesquisadora). Os demais necessitaram de todos os níveis da ajuda concreta e até dos seguintes níveis do gradiente de ajuda verbal: 3, no caso de Carlos e Breno; e 4, no caso de Cauique. Apesar de nem todas as crianças requererem todos os níveis de mediação verbal, todos os níveis de ajuda foram proporcionados aos participantes, no sentido de assegurar a igualdade de oportunidades e náo se distanciar da tese em que a pesquisa se baseou (Ribeiro, 2001).

A necessidade (ou não) do nível de mediação era identificada pela conduta da criança durante as jogadas subsequentes, que permitiam à pesquisadora verificar a eficácia da mediação anteriormente realizada. Dessa forma, se só o feedback náo fosse suficiente para a criança alterar sua conduta, a pesquisadora partia para o nível seguinte. Para definir o nível de mediação necessária, a pesquisadora observava as jogadas realizadas pelas crianças, buscava rastrear seus processos cognitivos, sua forma de jogar e verificar as habilidades que cada uma delas já dominava (nível de desenvolvimento real), para fazer intervençóes adequadas e otimizar a aprendizagem.

Ao analisar o que a criança já dominava, um aspecto interessante surgiu: embora algumas utilizassem termos como mamífero e ave já na fase de assistência indireta, não pareciam ter se apropriado efetivamente desses conceitos, fato evidenciado pelas perguntas, descartes e justificativas apresentados no decorrer das partidas. Tudo leva a crer, assim, que não haviam articulado os conceitos cotidianos com os científicos: apenas os tinham memorizado. Desse modo, depois de verificar o desenvolvimento real das crianças, a pesquisadora identificava a mediação que seria necessária para alcançar o nível de desenvolvimento próximo, tentando aumentar as possibilidades de sucesso durante o jogo.

De fato, a identificação de animais e de suas características comuns parece tê-los ajudado a formular perguntas mais abrangentes. Como as crianças mudaram sua conduta durante o jogo, tudo indica que essa forma de mediar parece ter 
surtido efeito: elas passaram a separar as figuras em blocos mediante uma característica comum, a fazer perguntas mais abrangentes e a realizar descartes mais corretos no decorrer das partidas.

Do gradiente de mediação, um dos níveis que mais propiciaram a aprendizagem foi a análise comparativa de estímulos em que as semelhanças e diferenças entre figuras eram analisadas. Esta conduta permitia à criança fazer classificaçóes mais precisas, partindo de conceitos cotidianos e de conhecimentos prévios para construir outros, novos. Igualmente eficiente foi a mediação por ajuda concreta. Depois de verem a pesquisadora descartar as figuras e organizá-las com base em um critério lógico, as crianças tendiam a imitá-la, embora de início ainda encontrassem dificuldades referentes à inclusão em classes. Essa alteração na forma de proceder das crianças evidencia a importância da imitação, conforme apontado por Vygotsky (1933, apud Elkonin, 1998), ao se referir ao jogo.

As crianças tentavam melhorar suas perguntas e ganhar o jogo imitando as ações da pesquisadora. Como explicado anteriormente, no marco teórico norteador desta pesquisa, Vygotsky esclarece que a criança nunca parte do zero ao imitar, mas, sim, de algo já criado, combinando-o, de forma inovadora, com a nova experiência. Alcança, assim, uma articulação entre o que já domina e o novo. Sob este aspecto, as crianças, ao imitarem a pesquisadora, não o faziam de forma mecânica: reconstruíam, individualmente, o que presenciavam, esforçando-se para seguir as regras (outra característica definidora do jogo) que a situação lhes impunha. As interações possibilitaram às crianças a articulação entre os sentidos (particulares) e os significados (públicos). Suas açóes eram re-significadas, reconstruídas e aprendizagens novas efetuadas.

No decorrer da fase de assistência direta e, no que se refere, especificamente, à troca de papéis entre as crianças, os dados apontam que, no caso de dupla simétrica, não foram observadas mudanças nas estratégias dos jogadores: trata-se, na verdade, mais de uma prática ou exercício de estratégias já dominadas. Nas duplas assimétricas, a melhora de desempenho de Rick, por exemplo, ao jogar com Cauique, indica que há maior possibilidade de se ganhar em aprendizagem, em razão das diferenças e não das semelhanças entre parceiros.

Ao se comparar como as crianças jogavam durante a fase de assistência indireta e do pós-teste, é possível verificar ganhos de aprendizagem: na assistência indireta, as crianças não organizavam as figuras de acordo com um critério lógico; prevaleciam perguntas ineficientes, e os descartes eram, em sua maioria, de qualidade intermediária (implícitos) ou de qualidade ineficiente (ausentes). Os conhecimen- 
tos prévios dos jogadores baseavam-se, na maior parte das vezes, na similaridade e no empírico. Posteriormente, no decorrer das partidas desenvolvidas com o apoio da mediação (assistência direta) as crianças passaram a: 1) separar os animais baseados em um atributo comum a todos; 2) agrupá-los dentro de conceitos mais amplos (mamíferos, aves e insetos, por exemplo); e 3) articular o que já sabiam pela experiência direta (seus conceitos cotidianos) com os novos conhecimentos adquiridos durante o jogo, por meio das interaçóes. Com isso, passaram a fazer perguntas mais abrangentes e descartes mais corretos, como se pode observar nos gráficos 1, 2, 3 e 4 (Anexo 1).

As crianças indicaram, portanto, que avançaram na aprendizagem, uma vez que, supostamente, transformavam o que era nível de desenvolvimento próximo em nível de desenvolvimento real. As estratégias cognitivas aprendidas durante a fase de assistência direta mantiveram-se e generalizaram-se quando jogaram com novas figuras, demonstrando que este pode ser um recurso para resolver problemas, com o apoio da mediação. Em outras palavras, o jogo parece favorecer a aprendizagem de novas estratégias e habilidades.

No que se refere à análise das condutas afetivas e das atitudes das crianças, os dados revelam que durante o jogo houve:

- Envolvimento: demonstravam alegria ao ganhar e, também, decepção ao perder. Exemplos:

Rick, na sua quinta partida com troca de papéis, depois de adivinhar $o$ animal escondido, deu um enorme sorriso de satisfação.

Carlos, na quarta partida da fase de assistência indireta, depois de fazer seis perguntas e perder a partida por não descobrir que a figura escondida era o coelho: "Ah, agora que eu ia falar o coelho!"

Esse fato corrobora a ideia de Vygotsky (1989) de que o jogo não necessariamente promove prazer, o que, na verdade, só ocorre quando se obtém sucesso.

- Concentração: excetuando-se Rick que, por algumas vezes, se distraía, as demais crianças mantiveram-se atentas às instruçóes e às jogadas. Exemplo: Rick, logo após a pesquisadora ter realizado um descarte: "Esta sala é de troféu?" (referindo-se aos troféus expostos em uma estante da biblioteca). A pesquisadora esclareceu que lá era a biblioteca da escola e pediu que prestasse atenção nas jogadas. 
- Rigidez moderada na forma de jogar, especialmente por parte de Rick e Carlos, o que dificultava a aprendizagem de novas estratégias cognitivas. Exemplo:

Rick, até a sua terceira partida na fase de troca de papéis, continuou a perguntar pelo nome dos animais em todas as jogadas, apesar das intervençóes da pesquisadora, demonstrando rigidez em sua conduta.

Carlos, por sua vez, até a segunda partida da fase de assistência, quando a pesquisadora lhe perguntou, mais uma vez, se não queria arrumar as figuras antes de começar a jogar, respondeu: "Não, perde-se muito tempo".

- Cooperação, especialmente por parte de Cauique e Breno, que aceitavam propostas e explicaçóes desde o início.

- Tranquilidade ao esperar o outro falar e jogar.

- Tolerância à frustração, particularmente no caso de Cauique e Breno.

Cauique, em sua primeira partida com troca de papéis, após saber que o animal escondido não era mamífero e não tinha pena apesar de ser um animal voador, pergunta: "É o porco?” Resposta: "Não." Apesar de ter perdido a partida, Cauique riu do próprio erro, quando a pesquisadora questionou: "Porco voa?" Ce: "Porco voando" (riu). P: "Você perguntou se tinha pena, eu disse que não. Perguntou se tinha pelo, também disse que não. Estes animais (apontando para os mamíferos e aves) tinham de ficar ou ir embora?" Ce: "Ir embora." P: "Você perguntou se voava, respondi que sim. Então quais poderiam ser?" Ce: (apontou para os insetos). P: "Como chama?" Ce: "Insetos." P: "Porco faz parte dos insetos?” Ce: (riu com o erro e disse que não).

Rick, apesar de se dispor a continuar jogando, independentemente do resultado obtido, quando teve Carlos como parceiro, foi induzido por ele ao erro. Ele reagiu, mostrando a figura escondida antes do término da partida. Com isso, impediu Carlos de ganhar, revelando seu desapontamento, raiva e frustraçáo com a atitude do adversário. Carlos, por sua vez, pareceu não reagir bem à frustração, tendo em vista tentar ganhar a qualquer preço. 


\section{CONSIDERAÇÕES FINAIS}

Os dados obtidos, analisados sob a perspectiva histórico-cultural, demonstraram que a utilização do jogo, atrelado a uma mediação social adequada, é um importante recurso para o professor verificar como seus alunos resolvem problemas; observar e rastrear seus processos cognitivos e, assim, conhecer um pouco melhor o que já dominam (nível de desenvolvimento real) e em que ainda precisam de ajuda (nível de desenvolvimento próximo). Nessas condiçóes, o jogo pode: possibilitar uma intervenção pertinente, atuando na ZDP; ativar o desenvolvimento de várias FPS; e otimizar as ocasióes de aprendizagem, o que pode ser constatado quando se observa a diferença de desempenho encontrada na fase de assistência indireta em relação às demais.

É interessante ainda observar a pertinência da colocação teórica dos autores adotados. Durante as partidas, foi possível verificar que as crianças estavam imitando a pesquisadora, não só em suas açóes como, também, nas palavras que usava para justificar perguntas e agrupamentos de figuras. Convém ressaltar, mais uma vez, que a imitação, para Vygotsky (1933, apud Elkonin, 1998), é uma das características essenciais do jogo. Assim, as crianças não repetiam simplesmente o que viam e/ou ouviam a adversária fazer, mas estavam reconstruindo, individualmente, o que aprenderam ao vê-la jogar. Logo, tudo indica que as crianças se apropriavam náo da ação ou das palavras da pesquisadora ou de outro adversário, mas reconstruíam o significado dessas açóes e palavras, uma vez que a simples repetiçáo das perguntas e açóes não lhes garantia o sucesso, tendo em vista que sua inserção, nas diferentes jogadas, dependia das cartas disponíveis a cada momento do jogo.

$\mathrm{Na}$ entrevista que a pesquisadora fez ao final da investigação, a importância dessa imitação também é revelada no relato das crianças, como no exemplo abaixo:

P: Teve algum momento que você achou que o jogo estava difícil?

Ce: Hum, hum.

P: Qual?

Ce: Quando eu não sabia separar os bichos.

P: E o que fez você aprender a separar os bichos?

Ce: Ver você jogando.

Com relação à troca de papéis entre as crianças, os dados ressaltam, no caso de dupla assimétrica, a necessidade de salientar duas possíveis situaçóes: a primeira refere-se à possibilidade de ganho em aprendizagem, como ocorreu, por exemplo, com Rick que, após ter jogado com Cauique, passou, tal como ele, não só a justi- 
ficar seus descartes, explicitando as inferências, como também deixou de realizar descartes inversos; já a segunda situação refere-se à possibilidade de ter o ganho em aprendizagem prejudicado, quando um dos membros da díade é inseguro e/ou facilmente influenciado pelo outro, que nem sempre está disposto a cooperar, fato que ocorreu com a dupla Carlos/Rick, pois o primeiro estava mais preocupado em se autoafirmar. Fica claro, portanto, que ao se formar duplas assimétricas com crianças não basta levar em consideração os níveis de desenvolvimento, para que ocorra uma mediação adequada; atitudes e condutas afetivas também devem ser ponderadas.

A importância de considerar as atitudes e a afetividade das crianças ao se estudar os aspectos cognitivos fica mais nítida quando se toma, por exemplo, o caso de Breno e, em especial, de Rick. Ao participar da pesquisa, ambos demonstravam insegurança, desmotivação e baixa autoestima diante das sucessivas dificuldades que enfrentavam na escola. No decorrer das partidas, conforme foi ocorrendo a mediação e, consequentemente, a modificação das condutas no jogo, pelas novas estratégias cognitivas que aprendiam, essas crianças puderam constatar os progressos que fizeram. Suas reaçóes mudaram radicalmente: passaram a se expor mais ao explicar como haviam chegado a determinada solução e, inclusive, a sorrir por verificarem que poderiam, sim, aprender.

Diante disso, o que se pode notar pelos dados obtidos é que, apesar de essas crianças não acompanharem a sala, do ponto de vista da aprendizagem escolar, ao utilizar o jogo com regras explícitas, com o apoio de uma mediação adequada, que leva em consideraçáo os níveis de desenvolvimento real e próximo, o desenvolvimento avança e amplia as possibilidades de aprendizagem, que se manifesta em melhor desempenho, aumentando as probabilidades de sucesso em novas situaçóes de jogo. Isto posto, é possível inferir que o jogo com regras explícitas e com apoio da mediação, ao ser utilizado no Ensino Fundamental, pode promover a aprendizagem e o desenvolvimento, bem como possibilitar trajetórias de sucesso no âmbito da escola.

\section{REFERÊNCIAS BIBLIOGRÁFICAS}

CAMPIONE, J. C. Assisted assessment: a taxomony of approaches and an outline of strengths and weaknesses. Journal of Learning Disabilities, v.22, n. 3, 1989.

CIVITA, Roberto et al. Os Bichos. São Paulo: Abril Cultural. v.1.

ELKONIN, Daniil. B. Psicologia do jogo. Tradução
Álvaro Cabral. São Paulo: Martins Fontes, 1998. FERRARA, R. A.; BROWN, A. L.; CAMPIONE, J. C. Children's learning and transfer of inductive reasoning rules: studies of proximal development. Child Development, v. 57, p. 10871099, 1986.

HAYWOOD, H. C.; SWITSKY, H. N. The 
Malleability of intelligence: cognitive process as function of polygenic - experiential interaction. School Psychology Review, v. 15, n.2, p. 245-255, 1986.

LEONTIEV, A. N. Os princípios psicológicos da brincadeira pré-escolar. In: VYGOTSKY, L. S.; LURIA, A. R.; LEONTIEV, A. N. Linguagem, desenvolvimento e aprendizagem. São Paulo: Ícone; Edusp, 1998.

LIDZ, C. S. Historical perspectives. In: Dynamic assessment: an interactional approach to evaluating learning potential. London: Guilford Press, 1987. p.3-34.

LINHARES, M. B. M. Avaliação assistida: fundamentos, definição, características e implicações para a avaliação asicológica. Psicologia: Teoria e Pesquisa, v. 1, n. 1, p. 23-31, jan./abr. 1995.

PINO, A. As Categorias do público e privado na análise do processo de internalização. Educação \& Sociedade, v. 13, n. 42, p. 315-327, ago. 1992.
RIBEIRO, M. P. de O. Funcionamento cognitivo de crianças com queixas de aprendizagem: jogando e aprendendo a jogar. 2001. Tese (Doutorado) - Instituto de Psicologia da Universidade de São Paulo, São Paulo.

STEIN, L. M. TDE - Teste de desempenho escolar: manual para aplicação e interpretação. São Paulo: Casa do Psicólogo, 1994.

TZURIEL, D.; KLEIN, P. S. Assessing the young child: children's analogical thinking modifiability. In: LIDZ, C. S. Dynamic assessment: an interactional approach to evaluating learning potential. London: Guilford Press, 1987. p. 268-287.

VAN DER VEER, R.; VALSINER, J. Vygotsky: uma síntese. São Paulo: Unimarco/Loyola, 1996.

VYGOTSKY, L. S. A Construção do pensamento e da linguagem. São Paulo: Martins Fontes, 2001. - El Desarrolo de los processos psicológicos superiores. 2.ed. Barcelona: Crítica, 1989. . A Formação social da mente. 5.ed. São Paulo: Martins Fontes, 1994.

Recebido em: fevereiro 2009

Aprovado para publicação em: fevereiro 2009 


\section{ANEXO 1}

Gráfico 1 - Desempenho de Breno durante a pesquisa

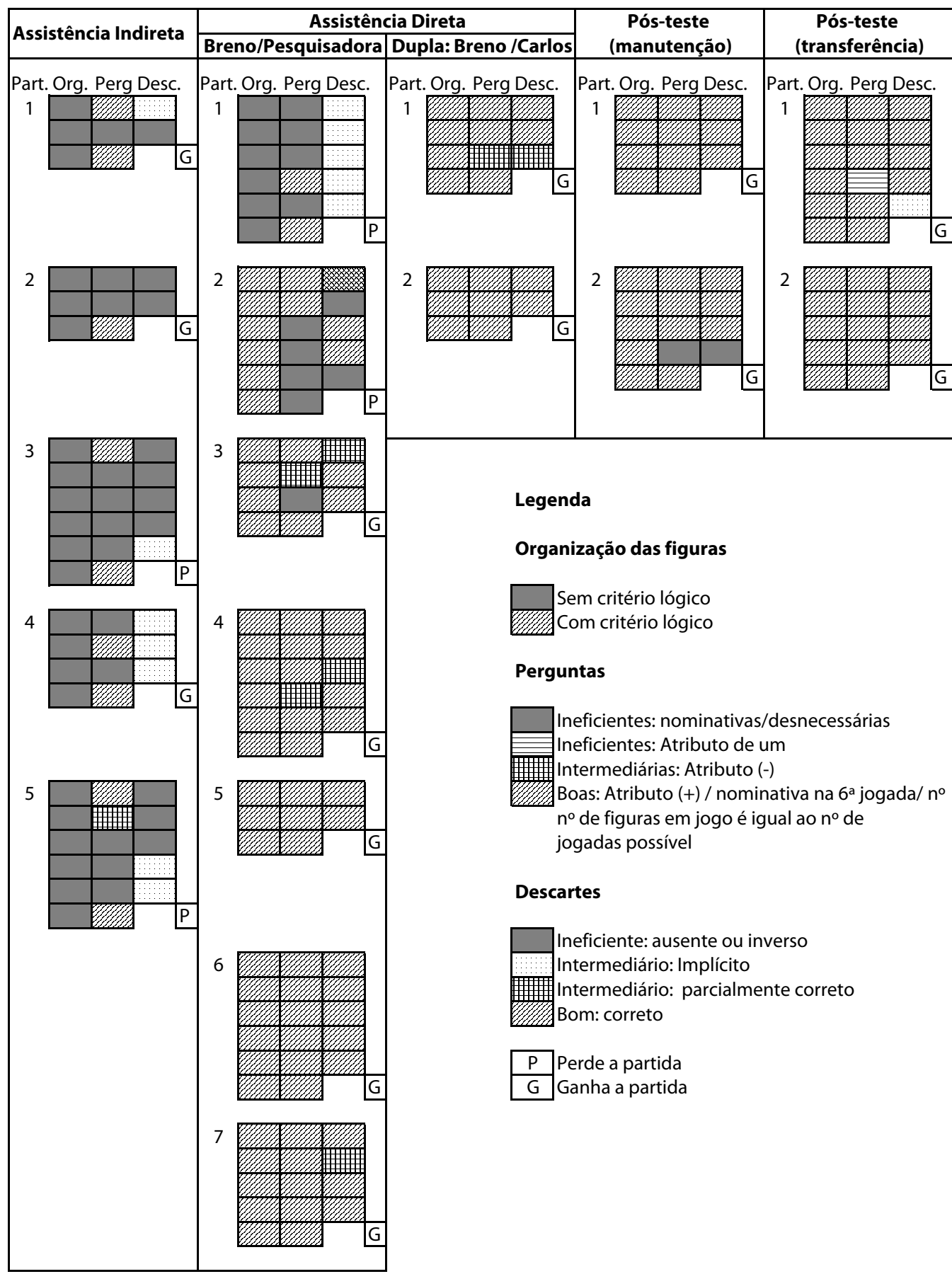


Gráfico 2 - Desempenho de Cauique durante a pesquisa

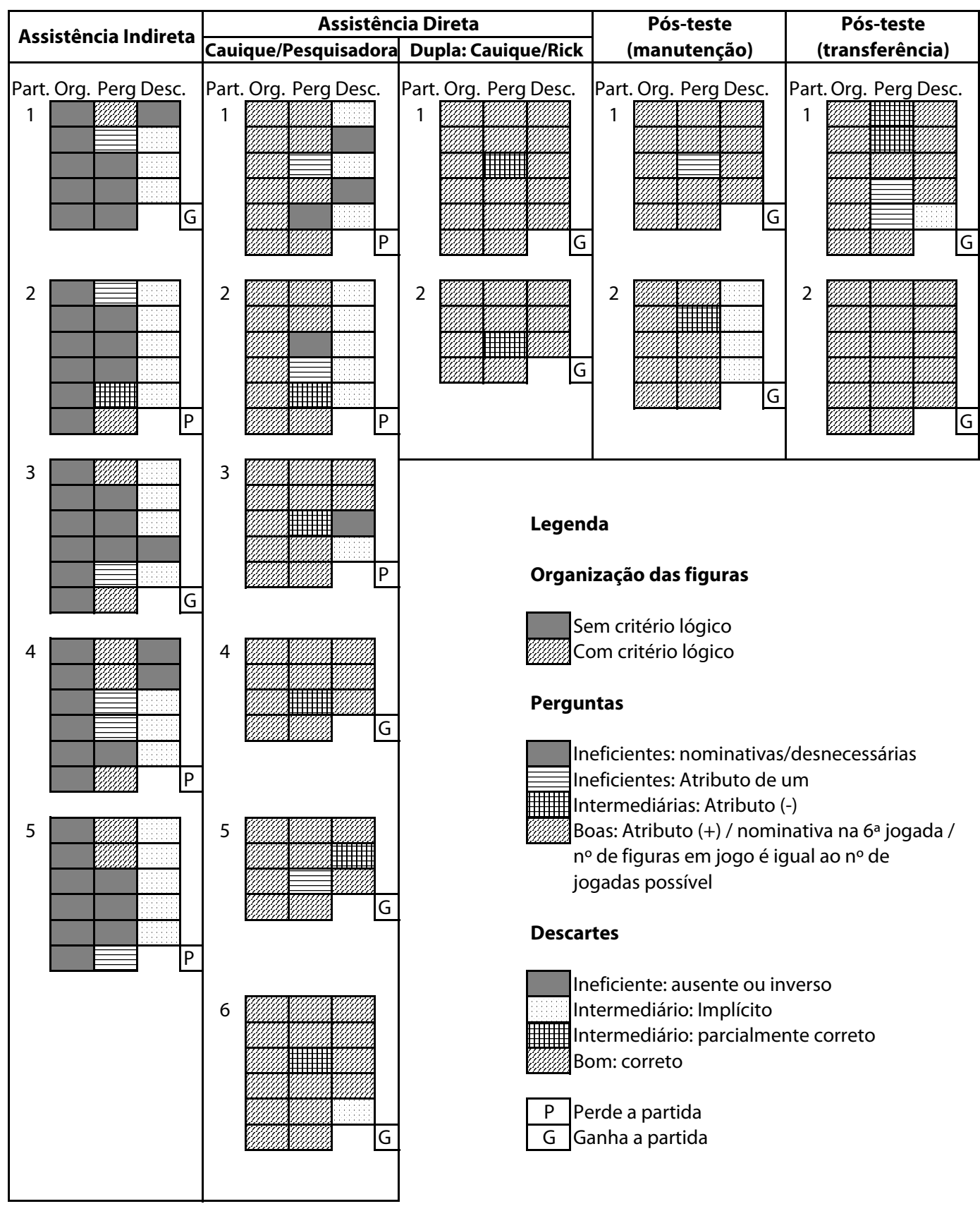


Gráfico 3 - Desempenho de Carlos durante a pesquisa

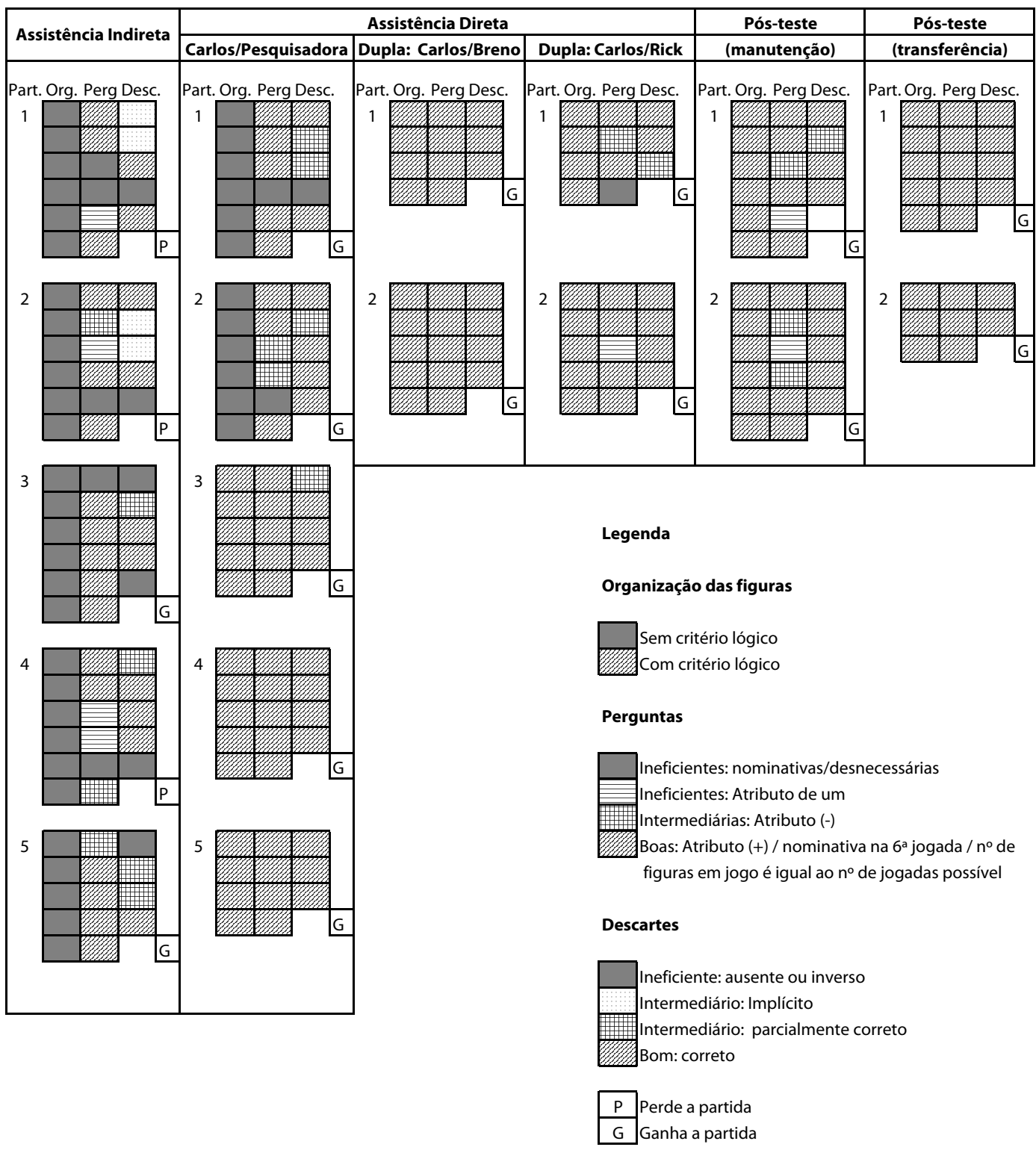


Gráfico 4 - Desempenho de Rick durante a pesquisa

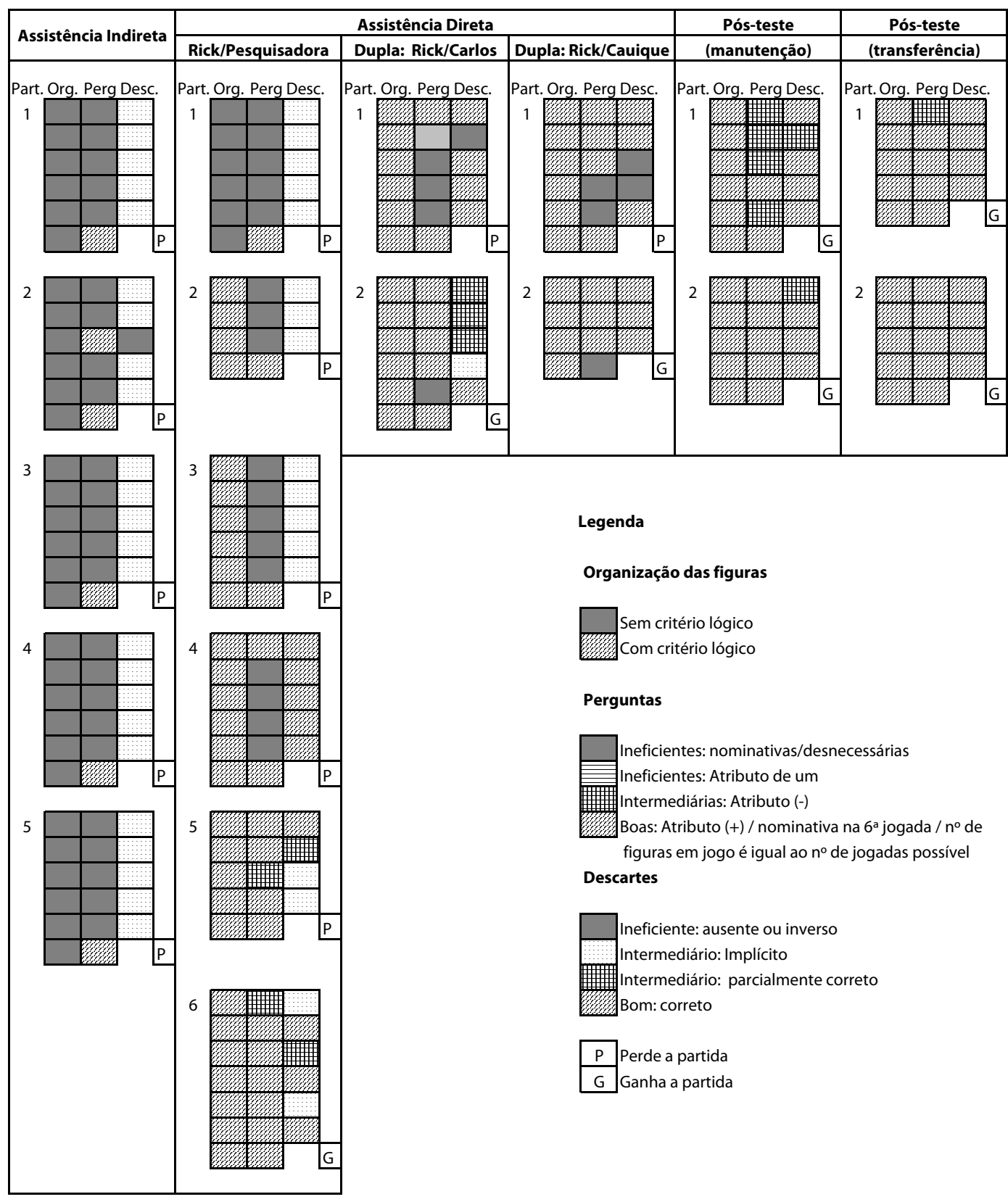

150 - Est. Aval. Educ., São Paulo, v. 20, n. 42, p. 125-150, jan./abr. 2009 